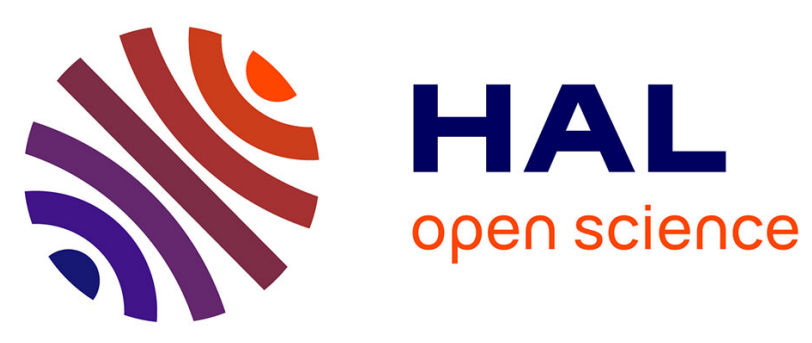

\title{
A decision-making framework based on knowledge criteria in network partner selection
}

Malihehsadat Vaezalaei, Ioana Deniaud, François Marmier, Didier Gourc, Robin Cowan

\section{- To cite this version:}

Malihehsadat Vaezalaei, Ioana Deniaud, François Marmier, Didier Gourc, Robin Cowan. A decisionmaking framework based on knowledge criteria in network partner selection. IESM 2019 - 8th International Conference on Industrial Engineering and Systems Management, Sep 2019, Shangai, China. 10.1109/IESM45758.2019.8948210 . hal-02380686

\section{HAL Id: hal-02380686 https://imt-mines-albi.hal.science/hal-02380686}

Submitted on 5 Feb 2020

HAL is a multi-disciplinary open access archive for the deposit and dissemination of scientific research documents, whether they are published or not. The documents may come from teaching and research institutions in France or abroad, or from public or private research centers.
L'archive ouverte pluridisciplinaire HAL, est destinée au dépôt et à la diffusion de documents scientifiques de niveau recherche, publiés ou non, émanant des établissements d'enseignement et de recherche français ou étrangers, des laboratoires publics ou privés.

$$
\text { Copyright }
$$




\section{A decision-making framework based on knowledge criteria for network partner selection}

\author{
Maliheh Vaez-Alaei* \\ BETA, CNRS UMR 7522 \\ Strasbourg University \\ Strasbourg, France \\ vaezalaei@unistra.fr
}

\author{
Ioana Deniaud \\ BETA, CNRS UMR 7522 \\ Strasbourg University \\ Strasbourg, France \\ deniaud@unistra.fr
}

\author{
Franois Marmier** \\ IMT Mines Albi, Industrial Engineering Center \\ Toulouse University \\ Albi, France \\ marmier@mines-albi.fr
}

\author{
Didier Gourc \\ IMT Mines Albi, Industrial Engineering Center \\ Toulouse University \\ Albi, France \\ gourc@mines-albi.fr
}

\author{
Robin Cowan \\ BETA, CNRS UMR 7522 \\ Strasbourg University \\ Strasbourg, France \\ cowan@unistra.fr
}

\begin{abstract}
In a complex project, an organization is often not able to manage all aspects alone, since it does not have all the required competences, skills or resources. In this case, alliance formation can be a solution for project development. Apart from simply managing complex projects, firms also find it important to increase innovativeness by sharing knowledge between partners in alliances. However, in alliances one of the difficulties is achieving effective collaboration: mis-communication, missing skills or missing resources create a high risk that the project fails to achieve its goals. In order to decrease the risk of failure, and to overcome potential collaboration inefficiency, partner selection takes place among firms that are able to communicate well while at the same time having the required knowledge to achieve their objectives. The important role of partner selection in alliances justifies the increased attention given to substantial criteria in alliance formation. Proposing a knowledge-based framework aimed at increasing the understanding of partner selection in alliances is the contribution of this paper. This knowledge can be gained by evaluating projects from a technological point of view to estimate their challenging degrees, and studying the partners background in past projects or partnerships. This paper structured to propose hypotheses based on a systematic literature review. At the heart of the hypotheses is a consideration of the needs of the project, and starting there allows us to characterize alliance formation and partner selection using a new typology. Finally, a novel framework is proposed that could help decisionmakers in the managerial aspects of partner selection in alliance formation. The framework also presents considerable potential for future studies.
\end{abstract}

Keywords-Alliances, innovation, partner selection, risk management, decision making

\section{INTRODUCTION}

Today, in order to improve, succeed, or even maintain the current position of an organization in this competitive world, innovation and utilizing new strategies are vital. Over the past decades, the literature has shown an increasing of interest in

\footnotetext{
* IMT Mines Albi, Industrial Engineering Center,Toulouse University,Albi, France.

** BETA, CNRS UMR 7522, Strasbourg University, Strasbourg, France. marmier@unistra.fr
}

strategic alliances as a strategy firms use in order to collaborate with others to increase innovativeness. Alliances permit firms to share different types of knowledge as a means of reaching a set of objectives, but at the same time maintaining a independence of the partner firm. [1] -[3]. Partners in an alliance combine diverse skills of to reach a set of predefined objectives. Notwithstanding the many (empirical and theoretical) claims regarding the value of alliances in innovating in complex projects, it should be noted that more than $60 \%$ of alliances fail [4]. Factors behind these failures are a lack of communication, leadership, cultural discrepancy, hidden objectives - in general issues of 'fit' between organizations. Partner selection therefore has a great impact on the success of a the project and on minimizing the risks attached to it. Therefore, the question How to select partners in alliances to maximize partners willingness and also chance of project's success simultaneously? has received considerable attention.

The role of similarity and complementarity in alliance formation is now a common theme in discussions of alliance success. Lai et al. [5] proposed that collaborators with more similarity along different dimensions - culture, learning ability, geographic distance and threat - are more likely to cooperate with each other. On the other hand divergence in relations leads to reluctance to cooperate. In addition, Lai et al. show that partners with complementary resources / skills or similar status, presumably are motivated to become partners in alliances [1]. Rosenkopf and Almeida [6] explored the direct relation between similarity of partners (in terms both of geography and technology) and alliance success or firms willingness to participate. They show that for partner selection, paying attention to the different characteristics of the organizations is critical. Therefore, the complementarity and similarity of these characteristics is one axis that should be considered when trying to understand partner selection and alliance success [7]. Success also depends, of course on the partnership being structured such that there is a fit among 
tasks, actors and resources. Quality of the match between the task and actors' resource increases the probability of allying [2].

Although previous research shows that partner commitment and interest are two keys for alliances success, partner selection plays decisive role in cooperation, and in a sense lies at the base of commitment and interest [3]. A classification by Gulati et al. [8] categorized partner selection based on different criteria : past collaboration experiences, resource compatibility, partners' status etc. A comprehensive model by application of two variables (cooperating similarity and competing similarity) are used to simulate strategic alliances by [9]. Regarding innovation, Mudambi et al. [10] argue that in alliance partner selection, knowledge similarity and close geographic distance have positive influences on final performance. Deniaud et al. [11] indicated that higher knowledge sharing among partners in a network increases the degree of innovation of a project. It is also discussed that evaluating projects to rank them as a technologically simple or challenging projects plays effective role in partner selection phase.

Nevertheless, there is still an important gap in designing a partner selection framework which considers multi knowledge criteria. The number of alliances is increasing due to the number of complex projects. In this context, there is an important need in decision making tools allowing to choose the best fit of partners.

In this paper, based on the overall review of previous research, we present a new approach for creating a partner selection framework that aims to maximize the chance of success in alliances. The remaining sections of this paper are organized as follows: Research methodology of this paper is indicated in section II Section III presents a literature review of previous research on partner selection. In section IV, theory and hypotheses regarding partner selection in alliances are provided. The proposed framework approach is explained in section V. The paper ends with a discussion and conclusion in section VI

\section{RESEARCH METHODOLOGY}

The phrase "strategic alliance" refers to a variety of (usually formalized) inter-firm partnerships [12] in which partner firms share resources to achieve pre-determined objectives, while maintaining independence. Research on strategic alliances has been very broad-based, ranging from ranging from human and social science, management and economic$\mathrm{s}$, to risk management and engineering science. The web of science counts more than 4400 papers that contain the phrase "strategic alliances" as a topic over the period 1994 to 2018 (ww.webofknowledge.com). Fig. 1 1 shows the number of papers which were published each year. From this corpus we have selected 50 papers using as criteria innovation, risk management partner selection and alliance formation. These form the basis for our analysis.

A brainstorm on the topic based on creativity and innovation is done to combine novel concept. In what follows we formulate hypotheses regarding partner selection based on a close

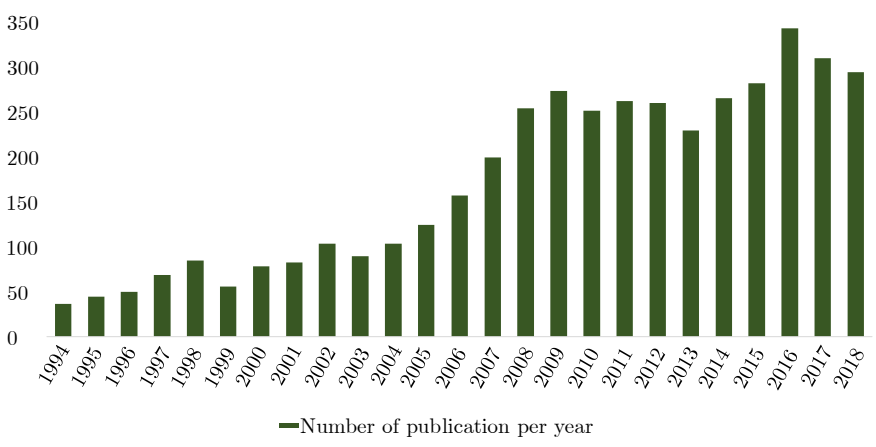

Fig. 1: Publication number per year based on searching "Strategic alliances" as a topic phrase in the Web of Science

reading of the literature. Then surveying the relevant studies is done, we classify them to fulfill the gap in strategic alliances literature.

The idea of this paper is to propose a novel framework for partner selection in strategic alliances. To do so, firstly we propose to evaluate the candidate firms based on their past experiences, and projects based on project complexity, then weighting the criteria to be considered for selecting the partners based on that evaluation.

\section{LITERATURE REVIEW}

Sharing knowledge in firms during collaboration leads to innovation, for most firms in most industries, innovation is needed to survive today. Nevertheless, firms collaborations are often very complex, and it is well-known that many alliances do not achieve their stated objectives. [4], [8]. In this section we present a systematic literature review on partners, projects and knowledge in alliance formation.

\section{A. Partners' past experiences}

"The more alliances you do, The better you get at them" [13]. This sentence, which means that organizations become more expert in alliance management with the past alliance experience, encapsulates the results of many studies in this field.

Partnership leads to learning and learning leads to growing knowledge, and increasing knowledge is a way to decrease the chance of failure in alliances [14]. It is also indicated that increasing knowledge is not enough to be successful, the important point is how to be motivated to convert this knowledge to the useful tools for communicational, managerial or technological aspects of a partnership. So, it might be concluded that past experiences can be an asset in alliances, if partners are motivated enough to work with each other. Sampson [15] used a sample data of R\&D alliances to discuss the learning ability of firms in their collaboration experiences and its effect on future partnerships. The results showed that although all organizations learn from cooperation and increase their knowledge, not all the gained knowledge is productive for the future alliances. According to this study, acquired 
knowledge mostly has a positive effect on future allies, but only for a short time after the alliance at issue, due to knowledge obsolesce.

Guardo and Harrigan asked whether a firm's past alliance experiences have a positive influence on the degree of innovativeness in future alliances [16]. They found that past learning is more effective when a firm displays a wide diversity of R\&D alliances. Emden et al. [17] concluded that learning orientation and organizational commitment to partnership are two criteria that affect firms' abilities to learn during and from an alliance. Thus these cultural factors can be considered central in determining the success of a alliance, and shape the way learning from past alliances feeds into future success.

According to the literature, there is a significant relationship between firms' past experiences and their future performance in collaborations. It is clear that this relationship is not direct, and lots of criteria affect it. One of the most influential criteria is knowledge criteria which are considered in this paper.

\section{B. Project complexity}

One of the characteristics that is central to determining the appropriate style for managing a project is complexity - its degree and nature. The role of complexity in project management is widely discussed in the literature. Project complexity is a criteria that has effects on the selection not only of organizational form and project management, but also of project goals such as time and cost [18]. One of the elements that turns a project in to a complex project is unexpected events due to the actors behaviour and projects characteristics. Complexity is often seen as one of the factors contributing to a project's failure, but at the same time, it is an inseparable part of almost any alliance [19]. To the extent that a project is complex, there is more uncertainty to deal with, and these uncertainties increase the risk of failure and the difficulties in estimating completion time, cost and quality [20]. Relich and Pawlewski [21] studied the relationships between past New Project Development (NPD) time and cost estimation, and developing new products. Previous data in organizational data-bases were considered as potential sources of information, and a neural network model was used to estimate cost of new product based on the past data. Nguyen et al. [22] demonstrated the impact of project complexity on resource allocation and project scheduling. In both cases it was concluded that project complexity has a direct relation with risks of failure.

The most commonly observed complexity in the project management literature are organizational complexity and technological complexity [18], [23]. Organizational complexity includes the relationships in respect of reporting, communicating between partners, task allocation etc. Technological complexity can be defined as a degree of challenge in processing inputs to outputs, this process including using skills, material, knowledge and techniques.

\section{Knowledge criteria}

New knowledge creation is critical for all firms, since knowledge enables the capacity for each firms and new knowledge enable the capacity for firms revival [24]. Every kinds of resources in a firm can be defined as knowledge. One of the most important goal of alliances is to share this knowledge to create innovativeness in different aspects of a project. Accordingly, when partners are going to be selected, it is necessary to evaluate their knowledge to find out their position in comparison with other firms. In this study, firm's knowledge position can be classified in three categories based on the literature and also new contribution: similarity, complementarity and coverage, which are explained in below and also depicted in Fig. 2 .

a) Similarity: Effective communication is a basic foundation for a prosperous cooperation between partners. Partners need to cooperate well in alliances, in order to succeed in complex projects. Similarity in knowledge is one of the most influential criteria which helps to avoid miscommunication and minimize the risk of failure in alliances.

Rosenkopf and Almeide [6] discussed knowledge localization in both geographical and technological aspects. They suggested that similarity in knowledge and also the mobility of firms can defeat the constraint in alliances. Cognitive similarity facilitates interaction, and helps the organization to build trust between partners [7]. Kim and Parkhe [9] developed a model using two variables based on similarity: competing similarity and cooperating similarity. A practical test by using sample of data applied to support stated hypotheses. Negative effect of competing similarity and positive effect of cooperating similarity is a part of their numerical results. One effective fact of alliance formation is partner's willingness to ally with each other. Similarity in foreign policies and geographic configuration localization can be a motivation for partners to forming alliances [25].

It can be concluded that knowledge similarity in partners causes a higher level in alliances capability ability and more effective relationships [4], [9]. The questions that might arise here are: Is it always advantageous for similar firms to ally? Are there other knowledge criteria that play a more effective role in alliances? What partner characteristics show us the importance of similarity? Hypotheses in this study are aimed at answering these questions.

b) Complementarity: Alliances will be created when there is an idea that firms in combination will have a greater effect than they will separately. Complementarity refers to the fact that knowledge stock are different from each other. In addition, the knowledge are different in way that means when they combine, they are greater than before.

Cobena et al. [26] analyzed the role of diversity in resources by considering data on airline alliances. Computational results showed that having recourse complementarity causes a better operational level performance in airlines alliance. Furlotti et al. [2] studied complementarity and similarity in alliance formation. Their results showed that there is a direct relation between the probability of allying firms, and adjustment among tasks 
and resources. They also noted that tasks should be considered in evaluating resource complementarity. Mostly it is indicated in the literature that sharing knowledge and learning between partners, has a direct influence on enhancing new product performance [11], [21]. A previous study, which used data from international mutual investment in China, suggested that knowledge absorption of partners plays a critical role in learning and innovation [27]. So the importance of knowledge complementarity is related to both project and partners characteristics.

c) Coverage: Needs of the project are a reason for different partners to ally and establish a network - to use others' knowledge, or to learn from knowledge sharing. So, learning is assumed as one of the most important reasons for making an alliance [28]. There are two factors which are important in selecting partners, first the willingness of partners to work with each other, and second to attain enough knowledge to do the project. We propose coverage as a new criteria in this study which shows all of the aggregated knowledge after alliance formation. Coverage contains both similarity and complementarity in knowledge.

There is a gap in the existing literature, which is the lack of study of knowledge criteria differences and their relationships with partners characteristics. Also, differences in the degree of project complexity have not yet received much attention. The difference between similarity, complementarity and coverage are depicted in Fig. 2, which serves as a schema for understanding how potential partners can position each other and the project's needs using these criteria, at the beginning of the project.

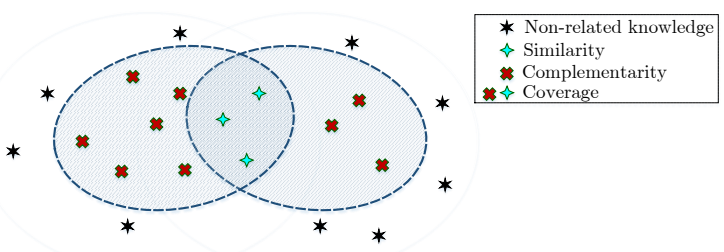

Fig. 2: Similarity, complementarity and coverage demonstration in two firms knowledge area

As an example, there are two firms in this figure with their own knowledge stocks, which are collaborating on a project. It should be noted, not all the knowledge in a firm is related to the collaboration. Among related knowledge there is some which is known by both firms, generating similarity; there is some knowledge related to the project that is known by only one or other of the firms, and this creates complementarity; all of the knowledge, similar or complementary, generates coverage. These knowledge criteria can be mathematically estimated, which are not discussed in this paper, but will be published as an extended version in future.

\section{THEORY AND HYPOTHESIS: PARTNER SELECTION}

In this research, two important characteristics are considered to define a framework for partner selection. First is to evaluate the project to know whether it is technologically simple or challenging. Second, to notice if partners know each other or it is their first collaboration. The idea of this paper is to choose the best partners for alliances by considering knowledge position and based on the evaluations of the stated characteristics. Besides partner selection, this evaluation helps in estimating project objectives like time and cost. The alliance formation methodology in divided into four steps: Identification the potential firms, evaluation them and select the best fit, negotiation with the selected partners and implementation the alliance [29]. In this study, we focus on the evaluation step and partner selection. The schematic view of alliance formation steps and our proposed framework is shown in Fig. 3

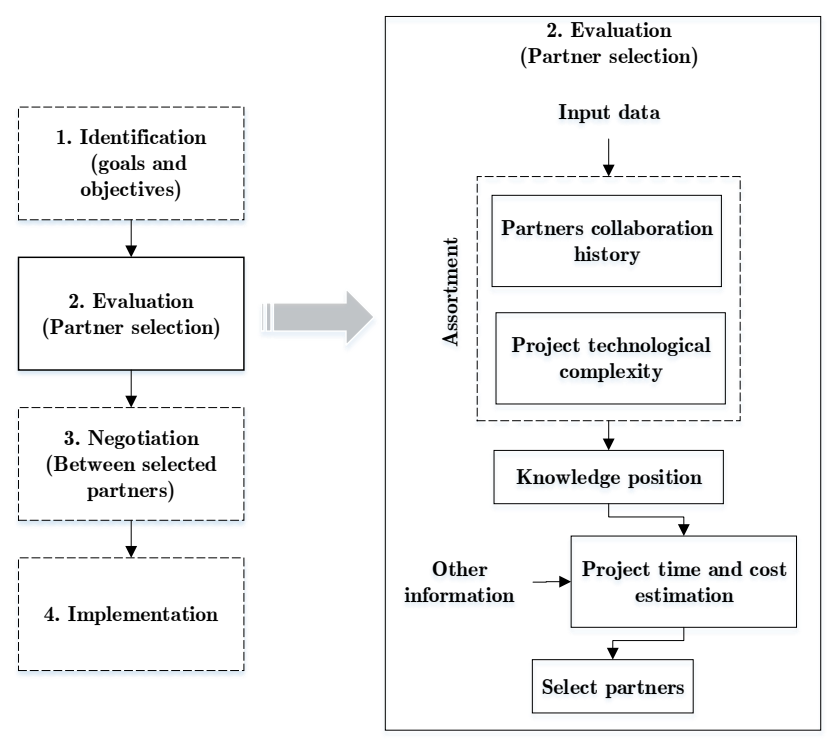

Fig. 3: A schematic overview of proposed framework

Based on the literature review and contributions about selecting partners in network of alliances, four hypotheses are proposed to design a framework in this paper.

Hypothesis 1: If the project is technologically simple and partners knew each other (and their past projects were successful), the budget and time can be estimated optimistically, and complementarity is more important.

Hypothesis 2: If the project is technologically simple but it is the first collaboration of partners / (or past projects had difficulties), the budget and time can be estimated optimistically, also similarity and complementarity are more important.

Hypothesis 3: If the project is technologically challenging and partners knew each other / past project was successful, the budget and time can be estimated pessimistically; also, complementarity and coverage are more important.

Hypothesis 4: If the project is technologically challenging but it is the first collaboration of partners / past project 
was with difficulties, the budget and time can be estimated pessimistically, also similarity, complementarity and coverage are important.

Studying the above hypotheses provides a starting point to design a partner selection decision-making tool to maximize the chance of success in a complex project.

\section{PROPOSED FRAMEWORK}

Each project is a context presenting specificities. A new project can be evaluated from the technological point of view to see whether it is simple or difficult (if there are some challenging activities). Moreover, a project can be done by partners having (successful or unsuccessful) collaboration in the past, or it could be their first collaboration. Then similarity, complementarity and coverage are defined as criteria to choose partners based on project context (Fig. 3). This suggested framework is presented in Table I.

The idea is considering similarity, complementarity and coverage at the same time but weighting them based of partners' characteristics. This criteria weighing based on knowledge is depicted in Fig. 4. As an example, similarity and coverage are more important than complementarity when we are describing a challenging project with new partners, whereas similarity is a critical criterion for communication between partners without past experiences. In addition, coverage of knowledge between firms creates more flexibility in management when project is technologically complex due to the more resources that they have in different firms [30].

To the best of our knowledge, this is the first paper that proposed a framework of knowledge criteria based on partner and project characteristic simultaneously.

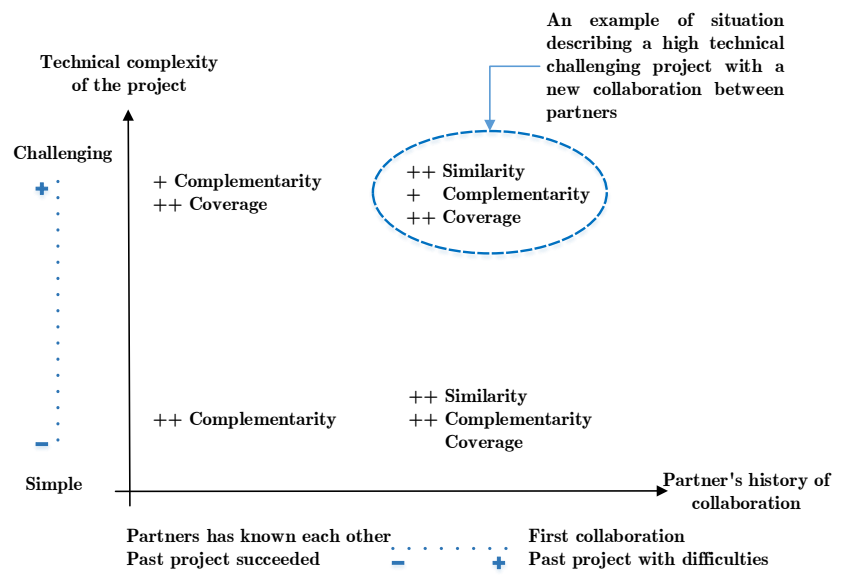

Fig. 4: An overview of criteria weighting based on knowledge

\section{DISCUSSION AND CONCLUSIONS}

In this paper we proposed a framework based on studying projects and partners in alliance formation. This research reviewed the previous studies in partner selection of alliance formation, and presented some new hypotheses, and also proposed a novel framework adapted to the needs of the project in order to help decision-makers maximize the chances of project's success, and minimizing the risk of failure. In this study two aspects are considered to be evaluated before selecting a partners for alliances. First, it is important to examine past experience of potential partners to know whether they have collaborated in the past. This part of the evaluation helps to know criteria will drive the next part of the process of partner selection, which looks at knowledge fit - complementarity, similarity and coverage. Second, it is also critical to evaluate the complexity of the project which is influential in partner selection based on their knowledge .

As an example based on the proposed framework, in partner selection phase of an alliances if the partners have known each other or their past project was a successful project, similarity in partner's knowledge/resources is not as important as complementarity and coverage, and this weighting between these criteria can change a little bit if the project is technologically simple or challenging.

\section{A. Future research}

This research can be seen as a starting point for future studies on the relationships between the aforementioned aspects and criteria to discuss and bring up more studies in order to support or reject the proposed hypotheses and to challenge this framework by data gathering, analyzing data or simulations. The current version of the framework can of course be further elaborated and customized to fit particular circumstances, supporting further criteria that may be relevant for alliance partner selection.

\section{B. Managerial insight}

The presented framework can be a useful tool for decisionmakers in real world projects, since it provides managers a concrete, evidence-based path with which to evaluate candidate alliance partners, to calculate innovation potential based on defined criteria, to choose the best combination of partners for alliance formation, and to estimate the time and budget of project more realistically.

Our purpose is that the proposed integrated framework can help in better understanding the relationship between project complexity, past experience of partners and their knowledge, the innovation potential of alliances and their chances of success. This should permit a stronger ability to form pertinent goals and so also to decrease the risk of failure in strategic alliances.

\section{ACKNOWLEDGMENT}

This study is a part of the project KAAT (Knowledge Alliance in Air Transport), which is under the support of the Erasmus and European Union. We have to express our appreciation to the all industrial partners of the project for their implication in the project. 
TABLE I: Proposed framework for partner selection based on knowledge

\begin{tabular}{|c|c|c|c|}
\hline & \multicolumn{2}{|c|}{ Alliance } \\
\hline & & $\begin{array}{l}\text { Partner has known each other and past } \\
\text { project succeeded }\end{array}$ & $\begin{array}{l}\text { First collaboration or past project with diffi- } \\
\text { culties }\end{array}$ \\
\hline \multirow[t]{2}{*}{$\begin{array}{l}\text { Technological } \\
\text { complexity of the } \\
\text { project }\end{array}$} & $\begin{array}{l}\text { Project technologi- } \\
\text { cally simple }\end{array}$ & $\begin{array}{l}\text { Confident with the optimist estimation for the } \\
\text { project } \\
\text { Select partners knowing that complementarity is } \\
\text { more important }\end{array}$ & $\begin{array}{l}\text { Confident with the optimist estimation for the } \\
\text { project } \\
\text { Select partners knowing that similarity and com- } \\
\text { plementarity are more important }\end{array}$ \\
\hline & $\begin{array}{l}\text { High technological } \\
\text { challenges }\end{array}$ & $\begin{array}{l}\text { Considering the pessimistically estimation for } \\
\text { the project } \\
\text { Select partners knowing that complementarity } \\
\text { and coverage are more important }\end{array}$ & $\begin{array}{l}\text { Considering the pessimistically estimation for } \\
\text { the project } \\
\text { Select partners knowing that similarity, comple- } \\
\text { mentarity and coverage are important }\end{array}$ \\
\hline
\end{tabular}

\section{REFERENCES}

[1] S. Chung, H. Singh, and K. Lee, "Complementarity, status similarity and social capital as drivers of alliance formation", Strategic management journal, 2000, 21(1), 1-22.

[2] M. Furlotti, and G. Soda, "Fit for the Task: Complementarity, Asymmetry, and Partner Selection in Alliances", Organization Science, 2018.

[3] W. Chen, and M. Goh, "Mechanism for cooperative partner selection: Dual-factor theory perspective", Computers \& Industrial Engineering, 2019, 128, 254-263.

[4] R. Bruner, and R. Spekman, "The dark side of alliances:: Lessons from VolvoRenault", European Management Journal, 1998, 16(2), 136-150.

[5] B. Lai, and D. Reiter, "Democracy, political similarity, and international alliances", Journal of Conflict Resolution, 2000, 44(2), 203-227.

[6] L. Rosenkopf, and P. Almeida, "Overcoming local search through alliances and mobility", Management Science, 2003, 49(6), 751-766.

[7] A. Capaldo, and A. M. Petruzzelli, "Partner geographic and organizational proximity and the innovative performance of knowledgecreating alliances", European Management Review, 2014, 11(1), 63-84.

[8] R. Gulati, F. Wohlgezogen, and P. Zhelyazkov, "The two facets of collaboration: Cooperation and coordination in strategic alliances", The Academy of Management Annals, 2012, 6(1), 531-583.

[9] J. Kim, and A. Parkhe, "Competing and cooperating similarity in global strategic alliances: an exploratory examination", British Journal of Management, 2009, 20(3), 363-376.

[10] S. M. Mudambi, and S. Tallman, "Make, buy or ally? Theoretical perspectives on knowledge process outsourcing through alliances", Journal of Management Studies, 2010, 47(8), 1434-1456.

[11] I. F. Deniaud, F. Marmier, D. Gourc, and X. Labaume, "How risks and innovativeness influence the selection of partner in NPD alliances", In Business Informatics (CBI), 2017 IEEE 19th Conference on (Vol. 1, pp. 62-69). IEEE.

[12] R. N. Osborn, and J. Hagedoorn, " The institutionalization and evolutionary dynamics of interorganizational alliances and networks", Academy of Management Journal, 1997 40(2), 261-278.

[13] J. R. Harbison, and P. Pekar Jr, "Smart alliances: A practical guide to repeatable success" (Vol. 2), 1998, Jossey-Bass.

[14] P. Braunerhjelm, "Entrepreneurship, Innovation and Economic Growthpast experience, current knowledge and policy implications", 2010.

[15] R. C. Sampson, "Experience, Learning \& Collaborative Returns in R\&D Alliances", 2002, Available at SSRN 309944.

[16] M. C. Di Guardo, and K. R. Harrigan, "Shaping the path to inventive activity: the role of past experience in R\&D alliances". The Journal of Technology Transfer, 2016, 41(2), 250-269.

[17] Z. Emden, A. Yaprak, and S. T. Cavusgil, "Learning from experience in international alliances: antecedents and firm performance implications", Journal of Business Research, 2005, 58(7), 883-892.

[18] D. Baccarini, "The concept of project complexitya review", Internationa journal of project management, 1996, 14(4), 201-204.

[19] J. Bakhshi, V. Ireland, and A. Gorod, "Clarifying the project complexity construct: Past, present and future',. International Journal of Project Management, 2016, 34(7), 1199-1213.

[20] L. A. Vidal, and F. Marle, "Understanding project complexity: implications on project management" Kybernetes, 2008, 37(8), 1094-1110.

[21] M. Relich, P. Pawlewski, "A case-based reasoning approach to cost estimation of new product development", Neurocomputing, 2018, 272, 40-45.
[22] L. D. Nguyen, L. Le-Hoai, D. Q. Tran, C. N. Dang, and C. V. Nguyen, "Effect of project complexity on cost and schedule performance in transportation projects", Construction Management and Economics, 2018, 1-15.

[23] H. Mintzberg, "The structuring of organizations", Strategic Management, 1989, (pp. 322-352). Palgrave, London.

[24] A. Inkpen, "Learning, knowledge acquisition, and strategic alliances", European Management Journal, 1998, 16(2), 223-229.

[25] B. Fordham, and P. Poast, "All alliances are multilateral: Rethinking alliance formation", Journal of Conflict Resolution, 2016, 60(5), 840865.

[26] M. Cobea, . Gallego, and C. Casanueva, "Heterogeneity, diversity and complementarity in alliance portfolios", European Management Journal, 2017, 35(4), 464-476.

[27] Z. Yao, Z. Yang, G. J. Fisher, C. Ma, and E. E. Fang, "Knowledge complementarity, knowledge absorption effectiveness, and new product performance: The exploration of international joint ventures in China", International Business Review, 2013, 22(1), 216-227.

[28] S. K. Muthusamy, and M. A. White, "Learning and knowledge transfer in strategic alliances: a social exchange view", Organization studies, 2005, 26(3), 415-441.

[29] J. R. Harbison, and P. Pekar, "Cross-border alliances in the age of collaboration", 1997, Los Angeles.

[30] N. B. Duncan "Capturing flexibility of information technology infrastructure: A study of resource characteristics and their measure", 1995 , Journal of management information systems, 12(2), 37-57. 